\title{
POPULATION ORGANIZATIONAL SYSTEMS AND REGULATORY \\ MECHANISMS OF A FOREST CARNIVORE (PINE MARTENS) \\ IN GRAND TETON NATIONAL PARK
}

Tim W. Clark

Department of Biology

Idaho State University

This report partially summarizes ongoing research between 1 November 1977 and 31 October 1978 that was funded by the University of WyomingNational Park Service Research Center and Grand Teton Natural History Association. The assistance and cooperation of several people is greatly appreciated: T. Hauptman, J. Weaver, T. Campbell, J. Hoak, P. Rathbun, W. Barnore, and D. Casey.

\section{Study Objectives}

The research is aimed at determining the role of animal behavior and environmental factors in regulating marten populations and social organization. The technique of systems analysis allows a model of the marten behavioral-ecological system (Fig. I) to be subdivided into individual components that can be examined in detail and later combined into a whole-system model. Specific hypotheses this model generated and methods of evaluation were presented by Clark (1977). At the least, this approach helps identify important elements of the system and factors requiring further research (Stromberg and Clark 1977).

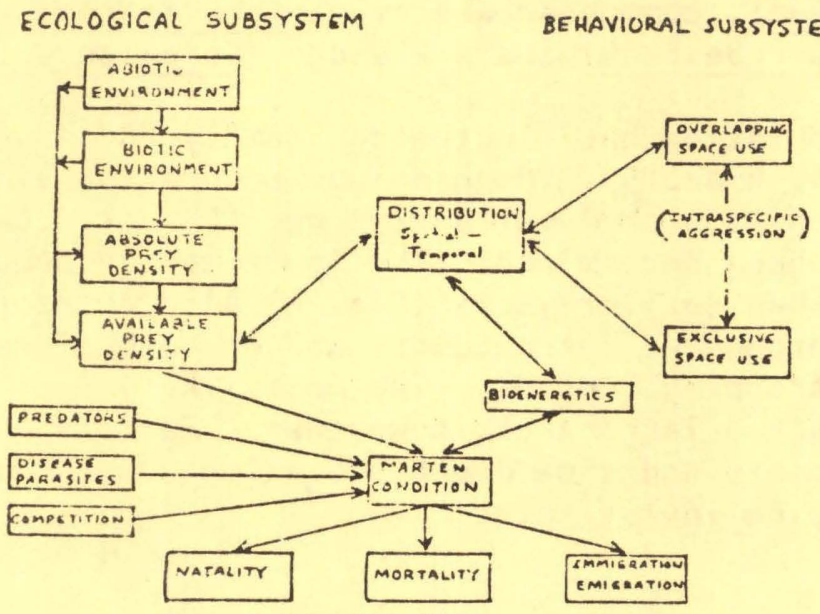

Figure 1. A schematic model of the pine marten behavioral-ecological system. 


\section{Methods}

Marten home range, movements, activity patterns and population composition are being determined by intensive live-trapping supplemented by radio telemetry.

Forested areas were classified into habitat types (Daubenmire and Daubenmire 1968) according to Steel et al. (1977).

\section{Study Area}

The $9.6 \mathrm{~km}^{2}$ study area is in Grand Teton National Park on a large forested bench at the base of the east slope of the Teton Range between the White Grass Ranch and Beaver Creek. Elevation is about $2200 \mathrm{~m}$. Annual temperatures average $2.4 \mathrm{C}$ (monthly range from $-9.9 \mathrm{C}$ to $15.7 \mathrm{C}$ ), with snow accounting for $70 \%$ of the annual precipitation of $61.5 \mathrm{~cm}(1950-1975$ data).

\section{Results and Discussion}

Eight male and 6 female marten were captured. One litter of two males was raised on the study area. Home range of an adult male and adult female are given in Figures 2 and 3 .

The area is largely a Abla/Cage Habitat Type, Vaccinium scoparium Phase that is complexly mixed with smaller areas of Abla/Vagl and Abla/Caru Habitat Types. Subalpine fir (Abies lasiocarpa) is the climax tree, but seral lodgepole pine (Pinus contorta) dominates the overstory. Understory dominants are grouse whortleberry (Vaccinium scoparium), tall huckleberry

(V. membranaceum), common snowberry (Symphoricarpos albus), pine grass (Calamagrostis rubescens) and elk sedge (Carex geyer $\mathrm{i}$ ).

The marten population has fluctuated monthly and annually between 1975 and 1978 (Figs. 4 and 5). Mean annual population size between 1975 and 1978 was 5.3 animals or 1 marten $/ 293$ ha $(733$ ac). Causes for the fluctuation have not been determined. The lower marten population on the study area in 1978 than earlier years (Fig. 4) also characterized marten populations throughout Teton County and on both sides of the Teton Range based on fur trapping records. The most likely factor that could influence marten over such a large area is weather. Factors such as moisture during preceeding summers and snow depth, duration and conditions may be important and are being investigated. 

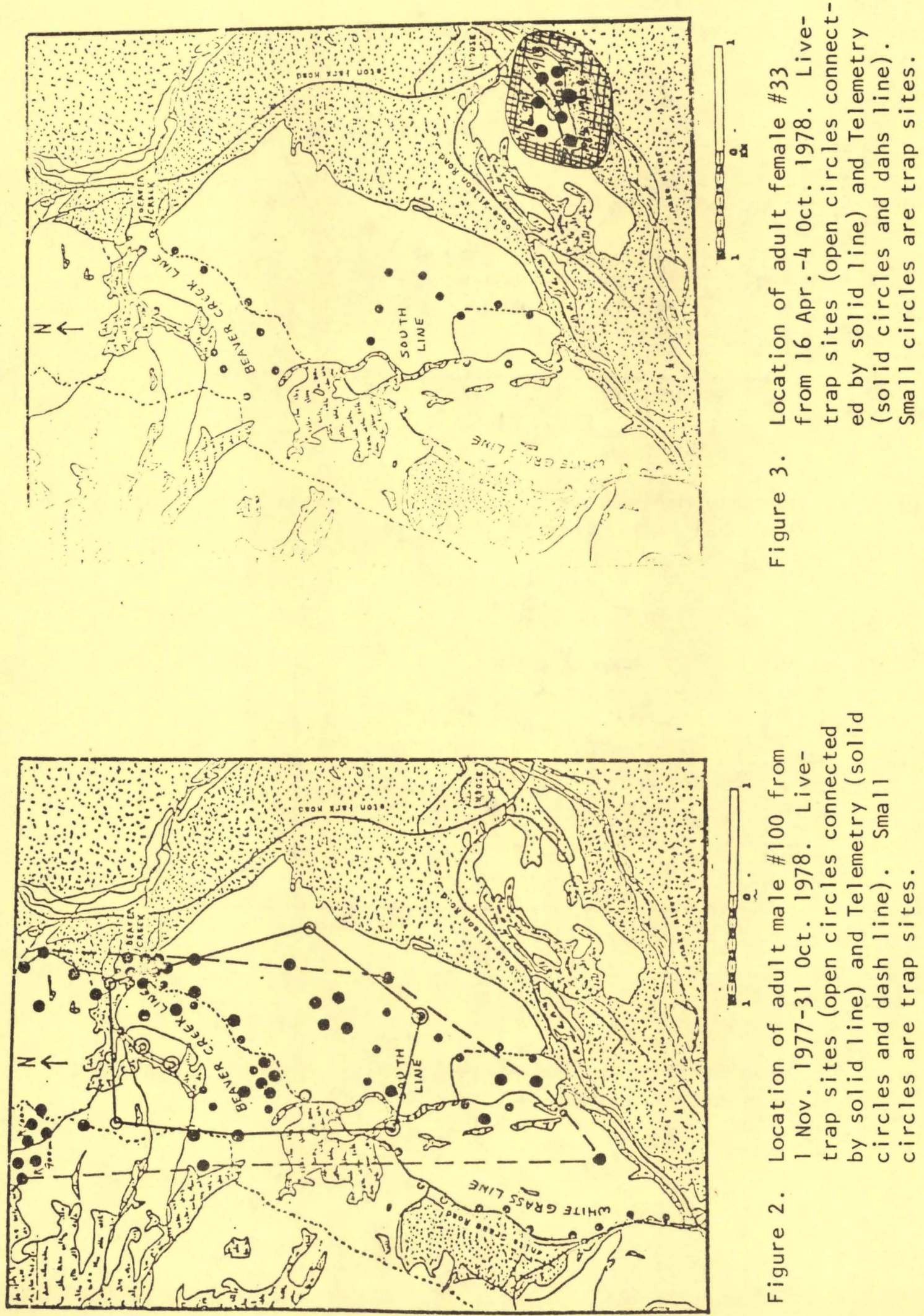

हิ $\rightarrow \frac{1}{4} \geq \pm 0$

○.

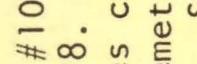
.

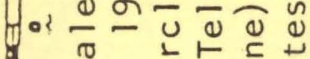

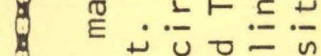

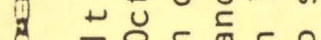

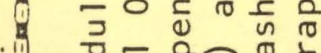
-

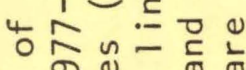
음ㅁำ 흥은

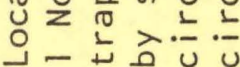




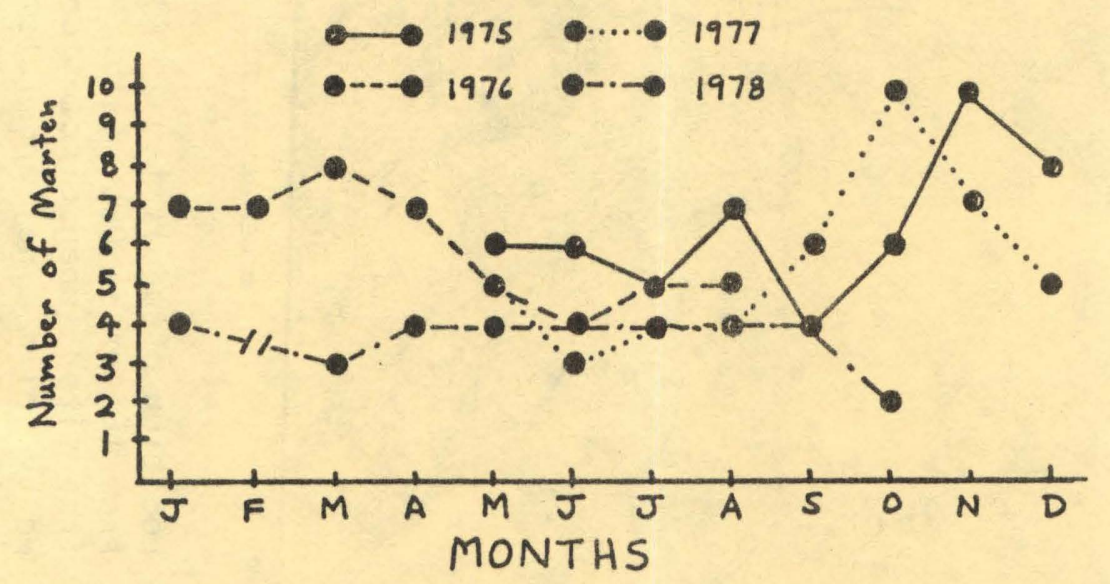

Figure 4. Monthly minimum marten population on the Grand Teton National Park, Wyoming study area.

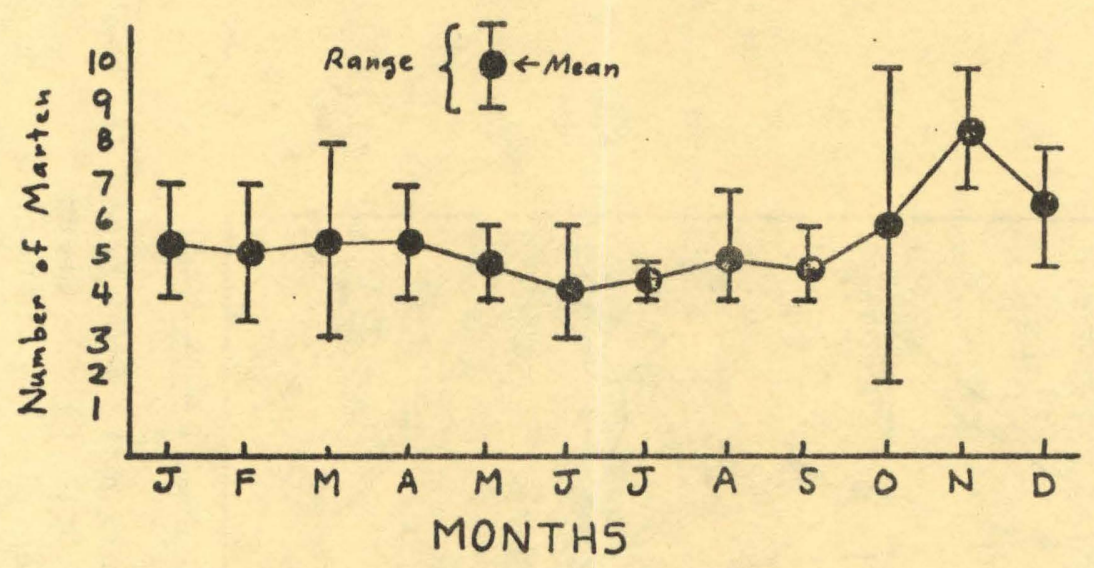

Figure 5. Mean monthly minimum marten population on the Grand Teton National Park, Wyoming study area, 1975-1978 


\section{Literature Cited}

Clark, T. W. 1977. Population organizational systems and regulatory mechanisms of a forest carnivore (pine martens) in Grand Teton National Park, Wyoming. Research Proposal, unpubl. 26pp.

Daubenmire, R. F. and J. B. Daubenmire. 1968. Forest vegetation of eastern Washington and northern Idaho. Wash. Agric. Exp. Sta. Tech. Bull. 60: 1-104.

Steele, R., D. Ondov, S. V. Cooper and R. D. Pfister. 1977. Preliminary forest habitat types of eastern Idaho and western Wyoming. USDA-FS Intermt. For. and Rg. Exp. Reg. 145pp.

Stromberg, M. R. and T. W. Clark. 1977. Black-footed ferrets and prairie dogs: simulation models in rare and endangered species management. In Clark, T. W. 1977. Black-footed ferrets and prairie dogs in Wyoming: 5 yr (1973-77) summary of research. Xerox 98pp. 